\title{
Article
}

\section{Multifunctional $\mathrm{GaFeO}_{3}$ Obtained via Mechanochemical Activation Followed by Calcination of Equimolar Nano-System $\mathrm{Ga}_{2} \mathrm{O}_{3}-\mathrm{Fe}_{2} \mathrm{O}_{3}$}

\author{
Lucian Diamandescu, Felicia Tolea *, Marcel Feder (D), Florin Vasiliu, Ionel Mercioniu, Monica Enculescu (D, \\ Traian Popescu and Bogdan Popescu
}

Citation: Diamandescu, L.; Tolea, F.; Feder, M.; Vasiliu, F.; Mercioniu, I.; Enculescu, M.; Popescu, T.; Popescu, B. Multifunctional $\mathrm{GaFeO}_{3}$ Obtained via Mechanochemical Activation Followed by Calcination of Equimolar Nano-System $\mathrm{Ga}_{2} \mathrm{O}_{3}-\mathrm{Fe}_{2} \mathrm{O}_{3}$.

Nanomaterials 2021, 11, 57.

https://doi.org/10.3390/nano11010057

Received: 14 November 2020

Accepted: 25 December 2020

Published: 29 December 2020

Publisher's Note: MDPI stays neutral with regard to jurisdictional claims in published maps and institutional affiliations.

Copyright: () 2020 by the authors. Licensee MDPI, Basel, Switzerland. This article is an open access article distributed under the terms and conditions of the Creative Commons Attribution (CC BY) license (https: / / creativecommons.org/ licenses/by/4.0/).
National Institute of Materials Physics, Atomistilor 405A, 077125 Magurele, Romania; diamand@infim.ro (L.D.); mfeder48@gmail.com (M.F.); fvasiliu@infim.ro (F.V.); imercioniu@infim.ro (I.M.); mdatcu@infim.ro (M.E.); tr.popescu@googlemail.com (T.P.); bogdan.popescu@infim.ro (B.P.)

* Correspondence: felicia.tolea@infim.ro

Abstract: The equimolar oxide mixture $\beta-\mathrm{Ga}_{2} \mathrm{O}_{3}-\alpha-\mathrm{Fe}_{2} \mathrm{O}_{3}$ was subjected to high-energy ball milling (HEBM) with the aim to obtain the nanoscaled $\mathrm{GaFeO}_{3}$ ortho-ferrite. X-ray diffraction, ${ }^{57} \mathrm{Fe}$ Mössbauer spectroscopy, and transmission electron microscopy were used to evidence the phase structure and evolution of the equimolar nano-system $\beta-\mathrm{Ga}_{2} \mathrm{O}_{3}-\alpha-\mathrm{Fe}_{2} \mathrm{O}_{3}$ under mechanochemical activation, either as-prepared or followed by subsequent calcination. The mechanical activation was performed for $2 \mathrm{~h}$ to $12 \mathrm{~h}$ in normal atmosphere. After $12 \mathrm{~h}$ of HEBM, only nanoscaled ( $20 \mathrm{~nm})$ gallium-doped $\alpha-\mathrm{Fe}_{2} \mathrm{O}_{3}$ was obtained. The $\mathrm{GaFeO}_{3}$ structure was obtained as single phase, merely after calcination at $950{ }^{\circ} \mathrm{C}$ for a couple of hours, of the sample being subjected to HEBM for $12 \mathrm{~h}$. This temperature is $450^{\circ} \mathrm{C}$ lower than used in the conventional solid phase reaction to obtain gallium orthoferrite. The optical and magnetic properties of representative nanoscaled samples, revealing their multifunctional character, were presented.

Keywords: $\mathrm{GaFeO}_{3}$; high-energy ball milling; Mössbauer spectroscopy; TEM; SAED; UV-vis optical and magnetic properties

\section{Introduction}

Gallium iron oxide, $\mathrm{GaFeO}_{3}$ (GFO), exhibits ferromagnetic and ferroelectric properties and has been studied for its promising applications as a multiferroic material [1]. This group of materials could have many applications, e.g., visible light water splitting [2] or a new random access memories generation. GFO crystallizes in the orthorhombic structure, space group (S.G.) number 33, Pna2 1 (Inorganic Crystal Structure Data (ICSD)). Commonly, the GFO is prepared by a solid-state reaction between $\beta-\mathrm{Ga}_{2} \mathrm{O}_{3}$ and $\alpha-\mathrm{Fe}_{2} \mathrm{O}_{3}$ at relative high temperature $\left(\sim 1400{ }^{\circ} \mathrm{C}\right)$ and long reaction time $(5-20 \mathrm{~h})$ [1]. $\mathrm{Ga}_{2} \mathrm{O}_{3}$ is an important wide band gap $\left(E_{g}>3 \mathrm{eV}\right)$ semiconducting material presenting five polymorphous $\alpha, \beta$, $\gamma, \delta$, and $\varepsilon$ phases. The $\beta-\mathrm{Ga}_{2} \mathrm{O}_{3}$ with monoclinic structure (ICSD, S.G. $12, \mathrm{C} 12 / \mathrm{m} \mathrm{1}$ ) is thermodynamically stable and used in optoelectronic devices [3], high-temperature gas sensors [4], and heterogeneous photocatalysis [5]. $\alpha-\mathrm{Fe}_{2} \mathrm{O}_{3}$ (hematite) is a versatile semiconducting material with applications from catalysis [6] and photocatalysis [7] to gas sensing [8], depending on morphology, preparation route and doping, owing to a favorable band gap energy $(2.1 \mathrm{eV})$, chemical stability, natural abundance, low cost, and no toxicity. $\alpha-\mathrm{Fe}_{2} \mathrm{O}_{3}$ crystallizes in the rhombohedral corundum structure (ICSD, S.G. 167, $\mathrm{R}^{-}{ }^{-}$).

Different preparation routes have been employed for obtaining GFO, such as solidstate reactions or chemical routes, which are shown to significantly influence the properties. Powders of $\mathrm{Ga}_{x} \mathrm{Fe}_{2-x} \mathrm{O}_{3}$ can be obtained by the conventional solid-state reaction technique [1] and a combination of reverse-micelle and sol-gel methods (RMSG) [9-11]. A modified Pechini method was proposed by T.C. Han et al. [12], where the obtained precursory powders were reground and sintered at $800{ }^{\circ} \mathrm{C}$ for $2 \mathrm{~h}$. Epitaxial GFO thin films 
were prepared via sol-gel method, exhibiting a high purity degree [13,14]. $\mathrm{GaFeO}_{3}$ as single crystal has been prepared using the high oxygen pressure floating zone method (HPFZ) [15]. GFO nanofibers [16] with different molar ratios of Ga:Fe were synthesized by sol-gel based electrospinning.

In the last few decades, the mechanical milling technique has been recognized as a method to obtain nanoscaled materials in which extended solid solutions or non-equilibrium phases can be formed at friendly temperatures [17-21]. Recent papers [22-24] report the synthesis of some ferrite systems directly by a high-energy ball milling technique (HEBM); e.g., starting with $\mathrm{ZnO}-\mathrm{Fe}_{2} \mathrm{O}_{3}$ [22], $\mathrm{La}_{2} \mathrm{O}_{3}-\mathrm{Fe}_{2} \mathrm{O}_{3}$ [23], $\mathrm{Eu}_{2} \mathrm{O}_{3}-\mathrm{Fe}_{2} \mathrm{O}_{3}$ [24] oxide mixtures, the HEBM process leads directly to the formation of $\mathrm{ZnFe}_{2} \mathrm{O}_{4}, \mathrm{LaFeO}_{3}$, and $\mathrm{EuFeO}_{3}$, respectively.

The primary goal of our study was to obtain GFO by only employing energetic ball milling. The first part of the paper reports on the attempt to obtain GFO by HEBM of the equimolar mixture $\beta-\mathrm{Ga}_{2} \mathrm{O}_{3}$ and $\alpha-\mathrm{Fe}_{2} \mathrm{O}_{3}$; the second part presents the successful synthesis of $\mathrm{GaFeO}_{3}$ by $\mathrm{HEBM}$ followed by calcination at temperatures hundreds of degrees lower than those required by the classical process. Compared to the sol-gel preparation route, which employs similar temperatures, much larger quantities of GFO can be easily obtained by our method. The phase evolution is presented along with the peculiar characteristics and properties of the initial, intermediate and final products.

\section{Materials and Methods}

Equimolar quantities of $\beta-\mathrm{Ga}_{2} \mathrm{O}_{3}$ (Fluka 99.99\%) and $\alpha-\mathrm{Fe}_{2} \mathrm{O}_{3}$ (Merck 99.5\%) were homogenized in acetone (magnetic stirrer), then evaporated at $50{ }^{\circ} \mathrm{C}$ on the drying stove. The HEBM process was performed in a SPEX $8000 \mathrm{M}$ device (SPEX SamplePrep LLC, Metuchen, NJ, USA) equipped with a motor working at $1435 \mathrm{rpm}(230 \mathrm{~V})$, for time periods ranging from 2 to $12 \mathrm{~h}$, at room temperature $\left(23^{\circ} \mathrm{C}\right)$. The experiments were performed in a hardened steel vial using $\frac{1}{2}$ in. and $\frac{1}{4}$ in. steel balls, at $10 / 1$ balls to powder mass ratio. Seven $1 / 4$ in. and three $1 / 2$ in. balls were used together in the HEBM experiments. Subsequently, the samples were subjected to thermal treatments, in the range of $600-1000{ }^{\circ} \mathrm{C}$ in an oven made by CALORIS GROUP SA, Bucharest, Romania.

Bruker D8 Advance X-ray diffractometer (Bruker, Hamburg, Germany) with $\mathrm{CuK}_{\alpha}$ radiation, $\lambda=1.5406 \AA$ and Lithium fluoride $(\mathrm{LiF})$ monochromator, was used to obtain the diffraction patterns of the prepared samples. The diffractograms were recorded at room temperature $\left(23^{\circ} \mathrm{C}\right)$ in Bragg-Brentano geometry. After a first evaluation using Bruker AXS DIFFRAC.EVA (Bruker AXS, Karlsruhe, Germany, 2000), Rietveld refinement was applied, in the hypothesis of Pseudo-Voigt profile of the lines. Transmission electron microscopy (TEM) was also employed to obtain specific information about the structure and morphology of the mixed oxide system. TEM and high resolution transmission electron microscopy (HRTEM) images were recorded on a JEOL JEM ARM $200 \mathrm{~F}$ electron microscope (JEOL Ltd, Tokyo, Japan), operating at an accelerating voltage of $200 \mathrm{kV}$. Samples for transmission electron microscopy (TEM) were prepared by suspending them in ethanol and transferring to a copper grid coated with an amorphous carbon support. The particles' sizes were established from the measurement of 100 particles for each sample.

The Mössbauer spectra were recorded at room temperature using a WissEL-ICE Oxford Mössbauer cryomagnetic system (Wissenschaftliche Elektronik GmbH, Starnberg, Germany, and ICE Innovative cryogenic system, Oxford, UK) with ${ }^{57}$ Co source in Rhodium matrix, in constant acceleration mode and velocity range $(-10-+10) \mathrm{mm} / \mathrm{s} . \alpha$-Iron foil was used to calibrate the spectrometer.

Optical properties of the investigated systems were revealed be UV-vis measurements. Reflection spectroscopy and an integrating sphere were used in order to study the optical properties of the samples, in a Perkin Elmer Lambda 45 spectrophotometer (Waltham, MA, USA). 
The magnetic measurements were performed with a superconducting quantum interference device (SQUID)—Quantum Design magnetometer (San Diego, CA, USA), in reciprocating sample oscillation (RSO) mode.

\section{Results and Discussion}

\subsection{Equimolar Mixture $\beta-\mathrm{Ga}_{2} \mathrm{O}_{3}$ and $\alpha-\mathrm{Fe}_{2} \mathrm{O}_{3}$ under $\mathrm{HEBM}$}

\subsubsection{X-Ray Diffraction}

Figure 1a-e represents the $\mathrm{X}$-ray diffraction $(\mathrm{XRD})$ patterns of the equimolar mixture $\beta-\mathrm{Ga}_{2} \mathrm{O}_{3}-\alpha-\mathrm{Fe}_{2} \mathrm{O}_{3}$, corresponding to milling times between 0 and $12 \mathrm{~h}$. At $0 \mathrm{~h}$ of milling (Figure 1a), one can see the patterns of beta gallium and alpha iron oxides to be milled. In Figure 1b-e, XRD patterns reveal a progressive peak broadening with milling time, commonly ascribed to the decrease in crystallite size of the oxides under milling. After $2 \mathrm{~h}$ of ball milling the reflection lines of gallium oxide cannot be observed anymore. This behavior can be explained by two effects: a dissolution of $\mathrm{Ga}^{3+}$ ions into the hematite lattice, easily proven by the relevant intensity increase of the 110 reflection of hematite line and a drop of the $c$ and a lattice constant (Figure 2), as well as by a small amorphization effect of gallium oxide due to HEBM process [25]. In Table 1, the lattice parameters, reliability $R$ factors [26], crystallite size, and phase content given by the Rietveld refinement of XRD patters for $\beta-\mathrm{Ga}_{2} \mathrm{O}_{3}-\alpha-\mathrm{Fe}_{2} \mathrm{O}_{3}$, subjected to HEBM from $2 \mathrm{~h}$ to $12 \mathrm{~h}$, are presented. A significant drop of crystallite size from $\sim 100$ to $\sim 15 \mathrm{~nm}$ after $12 \mathrm{~h}$ of milling can be observed. The lattice parameters $\mathbf{c}$ and $\mathbf{a}$ of hematite (Figure 2 and Table 1) decreased as the ball milling time increased, indicating the dissolution of $\mathrm{Ga}^{3+}$ ions in the hematite lattice $\left(\mathrm{Ga}^{3+}\right.$ ionic radius $\sim 0.62 \AA$ is smaller that of $\mathrm{Fe}^{3+}$ of about $0.67 \AA$ ). After $4 \mathrm{~h}$ or more of milling, the Ga- doped hematite is accompanied by a small amount (small percentage) of $\alpha$-Fe coming from the ball collision process during high energy milling.

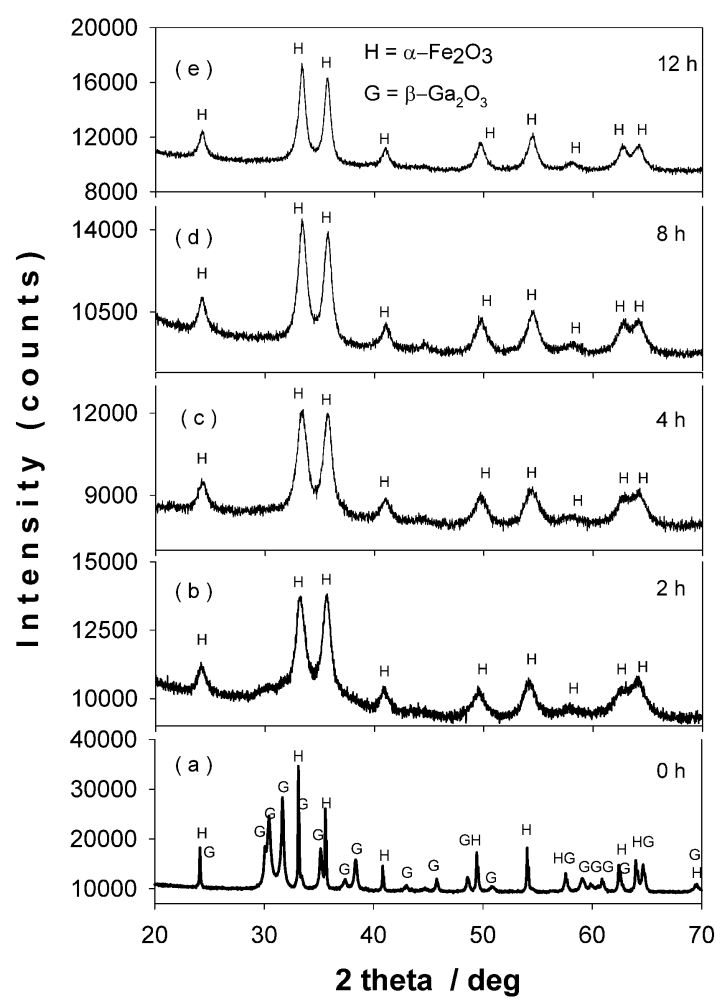

Figure 1. XRD patterns of the equimolar mixture $\beta-\mathrm{Ga}_{2} \mathrm{O}_{3}-\alpha-\mathrm{Fe}_{2} \mathrm{O}_{3}$, corresponding to milling times: (a) $0 \mathrm{~h},($ b) $2 \mathrm{~h},(\mathbf{c}) 4 \mathrm{~h},(\mathbf{d}) 8 \mathrm{~h}$ and (e) $12 \mathrm{~h}$. 


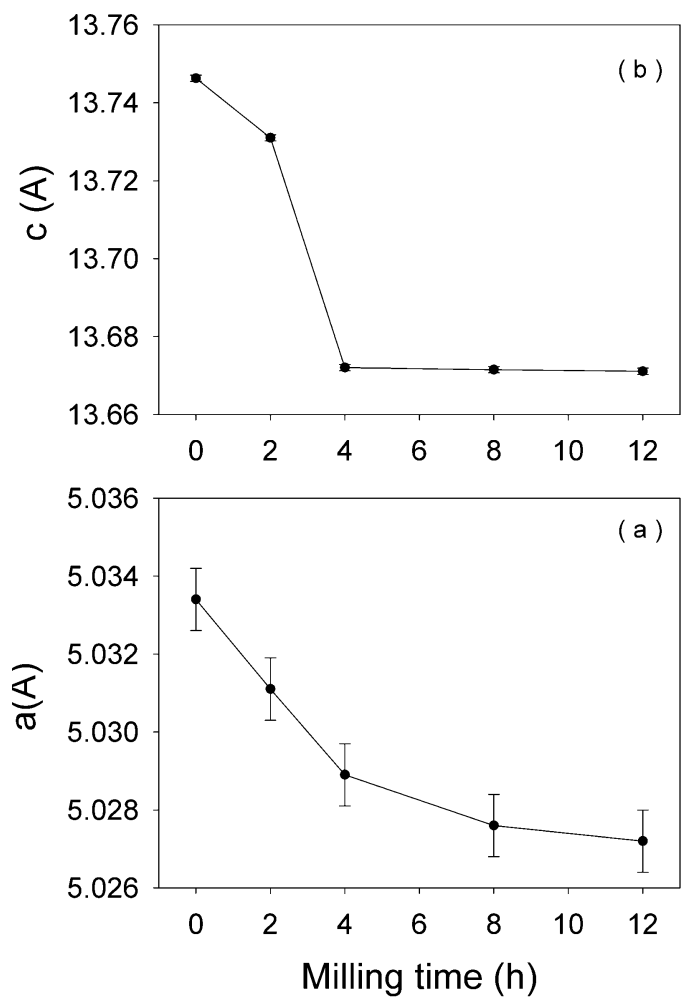

Figure 2. The lattice parameters $c$ and a of hematite, as function of the ball milling time; (a) stand for a lattice parameter and (b) for c lattice parameter.

Table 1. Lattice parameters, reliability $\mathrm{R}$ factors, crystallite size, and phase content in the Rietveld refinement of XRD patters for $\beta-\mathrm{Ga}_{2} \mathrm{O}_{3}-\alpha-\mathrm{Fe}_{2} \mathrm{O}_{3}$ (HEBM@0-12 h) system.

\begin{tabular}{|c|c|c|c|c|c|c|c|c|}
\hline \multirow{2}{*}{$\begin{array}{l}\text { Milling Time } \\
\text { (h) }\end{array}$} & \multicolumn{3}{|c|}{ Lattice Parameters (Å) } & \multicolumn{3}{|c|}{ Reliability R Factors (\%) } & \multirow{2}{*}{$\begin{array}{c}\text { Crystallite Size } \\
\text { (nm) }\end{array}$} & \multirow{2}{*}{ Phase Content (wt. \%) } \\
\hline & $a$ & $b$ & $c$ & $\mathbf{R}_{\mathrm{p}}$ & $\mathbf{R}_{\mathrm{wp}}$ & $\mathbf{R}_{\exp }$ & & \\
\hline \multirow{2}{*}{0} & 5.0334 & - & 13.7463 & \multirow{2}{*}{1.05} & \multirow{2}{*}{1.43} & \multirow{2}{*}{3.69} & $>100$ & $\alpha-\mathrm{Fe}_{2} \mathrm{O}_{3}(21.3)$ \\
\hline & 12.2143 & 3.0384 & 5.8084 & & & & $>100$ & $\beta-\mathrm{Ga}_{2} \mathrm{O}_{3}(78.7)$ \\
\hline 2 & 5.0311 & - & 13.7310 & 1.26 & 1.68 & 7.23 & 14.1 & $\mathrm{Ga}: \alpha-\mathrm{Fe}_{2} \mathrm{O}_{3}(100)$ \\
\hline \multirow{2}{*}{4} & 5.0289 & - & 13.672 & \multirow{2}{*}{1.15} & \multirow{2}{*}{1.51} & \multirow{2}{*}{7.44} & 12.2 & $\mathrm{Ga}: \alpha-\mathrm{Fe}_{2} \mathrm{O}_{3}(98.1)$ \\
\hline & 2.8640 & - & - & & & & 95.2 & $\alpha-\mathrm{Fe}(1.9)$ \\
\hline \multirow{2}{*}{8} & 5.0276 & - & 13.6715 & \multirow{2}{*}{1.29} & \multirow{2}{*}{1.77} & \multirow{2}{*}{8.14} & 13.9 & $\mathrm{Ga}: \alpha-\mathrm{Fe}_{2} \mathrm{O}_{3}(97.3)$ \\
\hline & 2.8690 & - & - & & & & 93.6 & $\alpha-\mathrm{Fe}(2.7)$ \\
\hline \multirow{2}{*}{12} & 5.0272 & - & 13.6711 & \multirow{2}{*}{1.05} & \multirow{2}{*}{1.43} & \multirow{2}{*}{8.94} & 15.6 & $\mathrm{Ga}: \alpha-\mathrm{Fe}_{2} \mathrm{O}_{3}(97.8)$ \\
\hline & 2.8589 & - & - & & & & 94.6 & $\alpha-\mathrm{Fe}(2.2)$ \\
\hline Errors & \pm 0.0005 & - & \pm 0.0005 & & & & \pm 1.5 & \pm 1.2 \\
\hline
\end{tabular}

\subsection{2. ${ }^{57} \mathrm{Fe}$ Mössbauer Spectroscopy}

The room temperature Mössbauer spectra, corresponding to $\beta-\mathrm{Ga}_{2} \mathrm{O}_{3}-\alpha-\mathrm{Fe}_{2} \mathrm{O}_{3}$ mixtures milled between $0 \mathrm{~h}$ and $12 \mathrm{~h}$ are displayed in Figure 3a-e. The characteristic Mössbauer hyperfine parameters (Isomer shift $\delta$, Quadrupole splitting $\Delta$, Hyperfine magnetic field $\mathrm{B}$, at the ${ }^{57} \mathrm{Fe}$ nucleus) phase assignment and relative abundance, given by the computer fit, are shown in Table 2. 


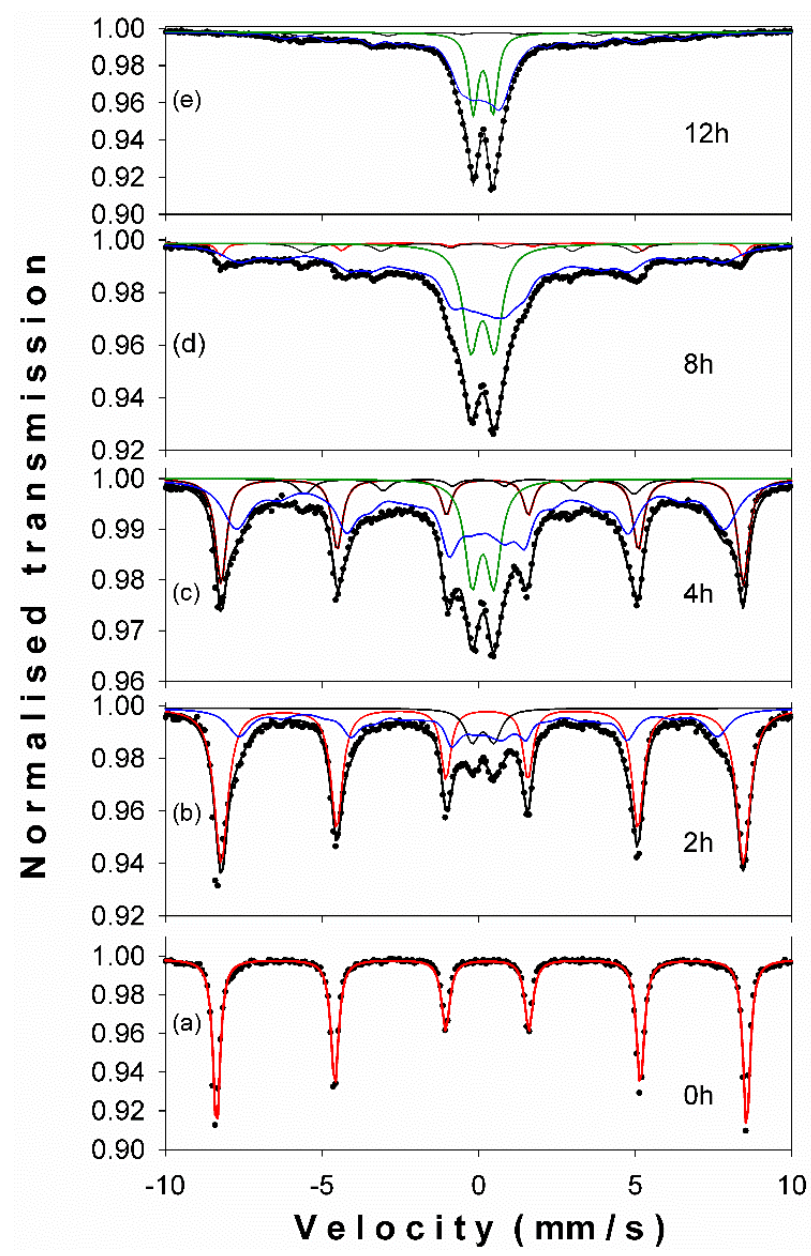

Figure 3. ${ }^{57} \mathrm{Fe}$ Mössbauer spectra recorded at room temperature for different ball milling times: (a) $0 \mathrm{~h},(\mathbf{b}) 2 \mathrm{~h}$, (c) $4 \mathrm{~h},(\mathbf{d}) 8 \mathrm{~h}$ and (e) $12 \mathrm{~h}$.

Table 2. Mössbauer hyperfine parameters for system $\beta-\mathrm{Ga}_{2} \mathrm{O}_{3}-\alpha-\mathrm{Fe}_{2} \mathrm{O}_{3}$, after HEBM.

\begin{tabular}{|c|c|c|c|c|c|}
\hline $\begin{array}{l}\text { Milling Time } \\
\text { (h) }\end{array}$ & $\delta *(\mathrm{~mm} / \mathrm{s})$ & $\Delta(\mathrm{mm} / \mathrm{s})$ & B (T) & Phase Assignment & $\begin{array}{c}\text { Relative } \\
\text { Abundance (\%) }\end{array}$ \\
\hline 0 & 0.288 & -0.209 & 52.4 & $\alpha-\mathrm{Fe}_{2} \mathrm{O}_{3}$ & 100 \\
\hline \multirow{3}{*}{2} & 0.293 & -0.178 & 51.7 & $\alpha-\mathrm{Fe}_{2} \mathrm{O}_{3}$ & 58.0 \\
\hline & 0.258 & -0.350 & $4.6-47.4$ & $\mathrm{Ga}: \alpha-\mathrm{Fe}_{2} \mathrm{O}_{3}$ & 35.7 \\
\hline & 0.254 & 0.705 & - & Paramagnetic & 6.3 \\
\hline \multirow{4}{*}{4} & 0.295 & -0.197 & 51.8 & $\alpha-\mathrm{Fe}_{2} \mathrm{O}_{3}$ & 23.4 \\
\hline & 0.262 & -0.231 & $5.7-48.3$ & $\mathrm{Ga}: \alpha-\mathrm{Fe}_{2} \mathrm{O}_{3}$ & 57.0 \\
\hline & 0.268 & -0.300 & 32.7 & $\alpha-\mathrm{Fe}$ & 5.0 \\
\hline & 0.254 & 0.699 & - & Paramagnetic & 14.6 \\
\hline \multirow{4}{*}{8} & 0.360 & -0.341 & 51.9 & $\alpha-\mathrm{Fe}_{2} \mathrm{O}_{3}$ & 3.0 \\
\hline & 0.293 & -0.243 & $5.5-47.9$ & $\mathrm{Ga}: \alpha-\mathrm{Fe}_{2} \mathrm{O}_{3}$ & 68.1 \\
\hline & 0.204 & -0.197 & 32.9 & $\alpha-\mathrm{Fe}$ & 5.1 \\
\hline & 0.244 & 0.760 & - & Paramagnetic & 23.8 \\
\hline \multirow{3}{*}{12} & 0.159 & -0.090 & $4.3-47.9$ & $\mathrm{Ga}: \alpha-\mathrm{Fe}_{2} \mathrm{O}_{3}$ & 71.0 \\
\hline & 0.334 & -0.362 & 33.2 & $\alpha-\mathrm{Fe}$ & 5.0 \\
\hline & 0.252 & 0.620 & - & Paramagnetic & 24.0 \\
\hline Errors & \pm 0.005 & \pm 0.010 & \pm 0.5 & & \pm 0.06 \\
\hline
\end{tabular}


At $0 \mathrm{~h}$ of milling, one can observe the typical six-line hematite pattern, with the characteristic negative quadrupole splitting $(\Delta)$ of $-0.21 \mathrm{~mm} / \mathrm{s}$ and a hyperfine magnetic field (B) of about $52 \mathrm{~T}$. As the milling time increases, the Mössbauer spectra change. For $2 \mathrm{~h}$ of ball milling time, the Mössbauer spectrum was deconvoluted in a sextet corresponding to standard hematite, a hyperfine magnetic field distribution reflecting the disorder induced by the presence of gallium ions in the hematite lattice, and a central quadrupole doublet (paramagnetic phase, abundance of $\sim 6 \%$ ) coming from the contribution of nanoscaled hematite particles in the sample. After $4 \mathrm{~h}$ of milling (Figure 3c) the phase structure changes with a drop of pure hematite phase to $23 \%$, accompanied by an increase of the hyperfine field distribution component up to $\sim 57 \%$ and of paramagnetic phase to $\sim 14 \%$. In good agreement with XRD data, one can observe the presence of $\alpha$-Fe phase $(\sim 5 \%)$ represented by a characteristic sextet with $\mathrm{B} \approx 33 \mathrm{~T}$. For $8 \mathrm{~h}$ of ball milling time, the pure hematite phase dropped to $\sim 3 \%$, the hyperfine magnetic field distribution phase reached $68 \%$ from the spectrum area and the paramagnetic phase (central doublet) grew up to $24 \%$, in agreement with the crystallite size drop in the system, as revealed by XRD refinements (Table 1). The magnetic gallium-doped hematite phase reached $71 \%$ after $12 \mathrm{~h}$ of milling (Figure 3e), while the paramagnetic phase was close to $24 \%$, few percent belonging to the $\alpha$-Fe phase. The evolution of the paramagnetic and magnetic phases percent, during the ball milling process of the equimolar mixture of $\beta-\mathrm{Ga}_{2} \mathrm{O}_{3}-\alpha-\mathrm{Fe}_{2} \mathrm{O}_{3}$, is displayed in Figure 4 . The increased paramagnetic phase, with ball milling time, is a consequence of crystallite size dropping. This phase is actually a gallium-doped hematite but with very small particle sizes $(<7 \mathrm{~nm})$. The phase evolution in the studied system is presented versus ball milling time in Figure 5. One can notice the quantitative decrease of the pure hematite phase and the progressive increase of the Ga-doped phase, as the milling time increases. Based on the above XRD and Mössbauer data, we can claim the facile synthesis of gallium-doped nanoscaled hematite, even at high molar contents of gallium.

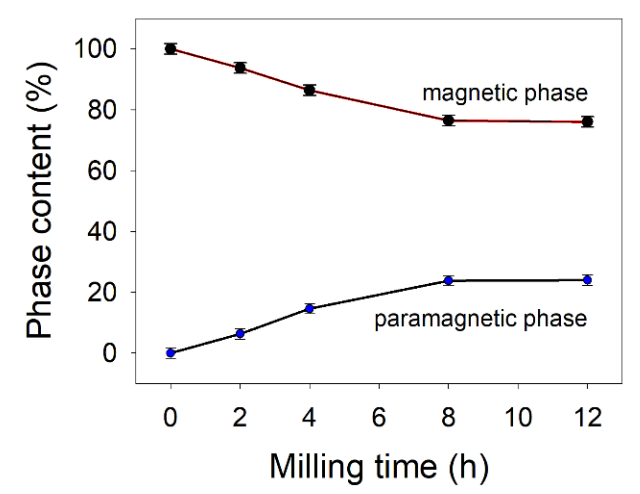

Figure 4. The evolution of paramagnetic to magnetic phases during the ball milling process.

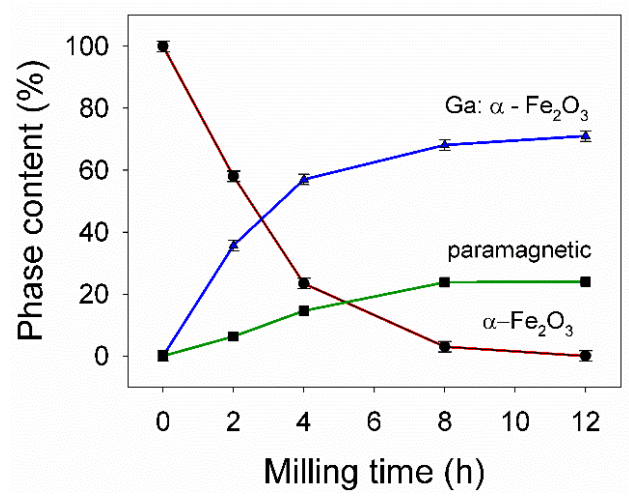

Figure 5. The phase evolution versus ball milling time. 


\subsubsection{TEM}

A general morphology image of the Ga-doped hematite sample after $12 \mathrm{~h}$ of ball milling time is given in Figure 6. The nano-particles' structure can be noticed. Moreover, the mean particle size is of about $\sim 20 \mathrm{~nm}$, which is in agreement with the XRD results.

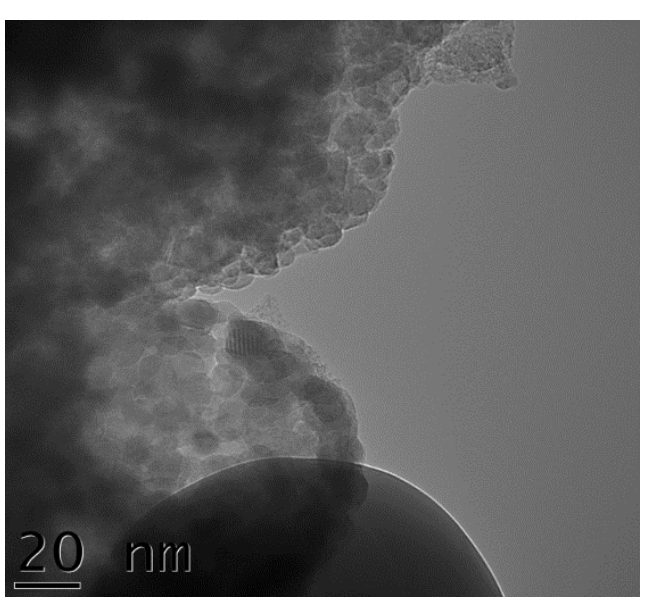

(a)

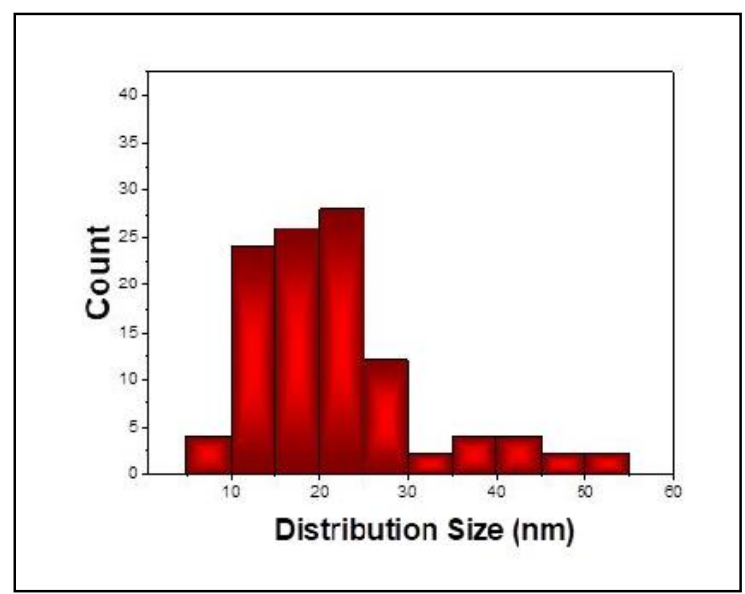

(b)

Figure 6. (a) TEM image on the gallium-doped hematite sample after $12 \mathrm{~h}$ of ball milling, and (b) the histogram for particle size distribution in the sample.

\subsection{Obtaining and Characterizing the $\mathrm{GaFeO}_{3}$ (GFO)}

The data presented in Section 3.1 demonstrate that in the case of equimolar oxide mixture, $\beta-\mathrm{Ga}_{2} \mathrm{O}_{3}-\alpha-\mathrm{Fe}_{2} \mathrm{O}_{3}$, the energy generated by HEBM in the system was not enough to directly produce the crystallization of $\mathrm{GaFeO}_{3}$. Consequently, a series of calcinations up to $1000{ }^{\circ} \mathrm{C}$ was performed to find out the optimum temperature for the desired crystallization of $\mathrm{GaFeO}_{3}$.

\subsubsection{XRD Data}

Figure 7a-e shows the XRD patterns of the sample after $12 \mathrm{~h}$ of ball milling calcined at different temperatures in the range of $600-950{ }^{\circ} \mathrm{C}$.

Table 3 presents the lattice parameters, reliability R factors, crystallite sizes, and the phase content of the calcined samples as resulted from Rietveld structural refinements. At $600{ }^{\circ} \mathrm{C}$ and $800^{\circ} \mathrm{C}$ (Figure 7a,b) only the nanoscaled gallium-doped hematite pattern can be observed. The crystallite size increases from $\sim 21 \mathrm{~nm}$ at $600{ }^{\circ} \mathrm{C}$ to $\sim 62 \mathrm{~nm}$ at $800{ }^{\circ} \mathrm{C}$. The thermal treatment at $850{ }^{\circ} \mathrm{C}$ (Figure 7c) reveals the initiation of $\mathrm{GaFeO}_{3}$ formation $(\sim 13 \mathrm{wt}$. \%) with the persistence of gallium-doped hematite ( $75 \mathrm{wt}$. \%). One can remark the unexpected appearance of $\beta-\mathrm{Ga}_{2} \mathrm{O}_{3}$ phase $(\sim 12 \mathrm{wt}$. \%) in the XRD pattern of the sample calcined at $850{ }^{\circ} \mathrm{C}$. The XRD pattern of the sample calcined at $900{ }^{\circ} \mathrm{C}$ (Figure $7 \mathrm{~d}$ ) consists in a prevailing GFO phase ( $\sim 69 \mathrm{wt}$. \%) together with gallium-doped hematite and small amounts of $\beta-\mathrm{Ga}_{2} \mathrm{O}_{3}$. At $950{ }^{\circ} \mathrm{C}$ (Figure 7e), the XRD pattern indicates only the presence of the single $\mathrm{GaFeO}_{3}$ phase. The calcination at $1000{ }^{\circ} \mathrm{C}$ leads also to the single phase of gallium orthoferrite with crystallite size greater than $100 \mathrm{~nm}$. 


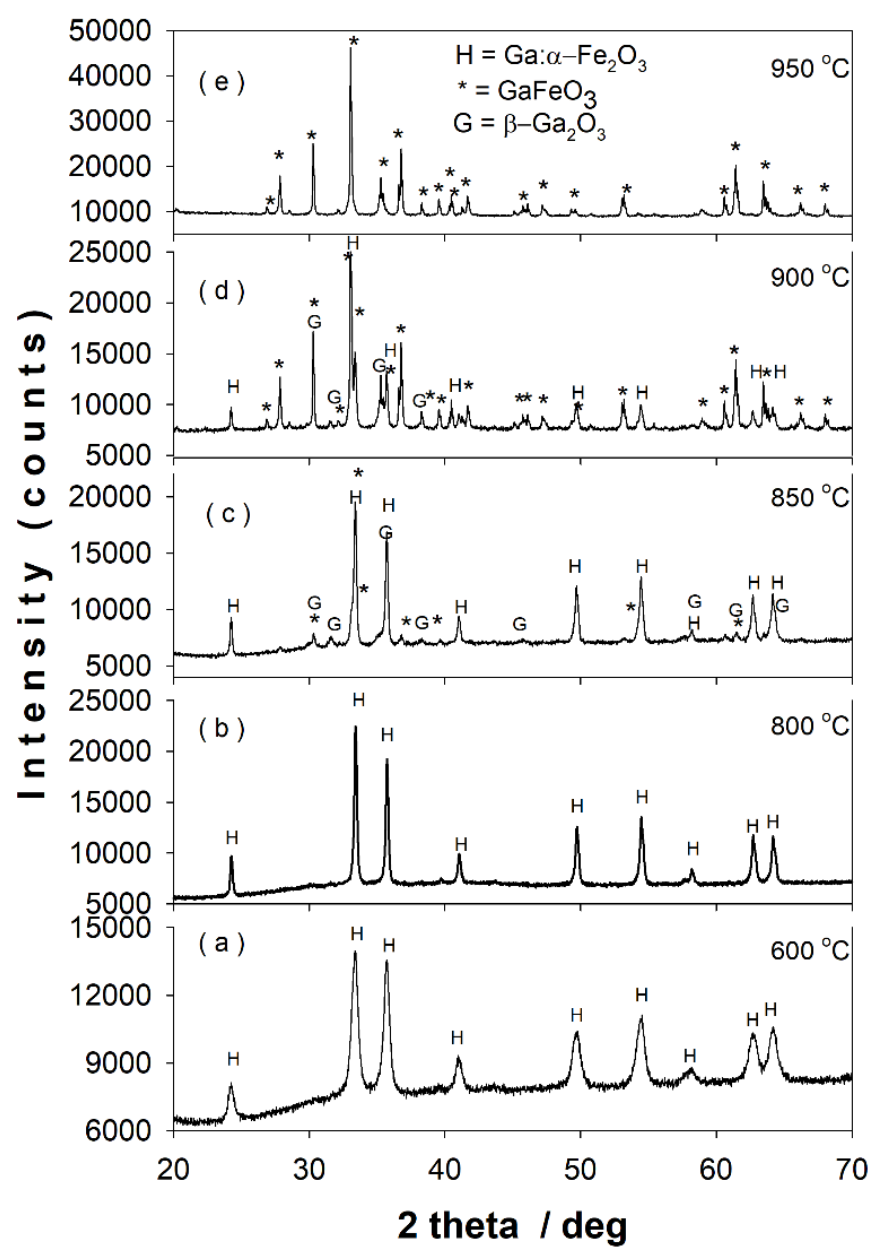

Figure 7. XRD patterns of the sample after $12 \mathrm{~h}$ of ball milling calcined at (a) $600{ }^{\circ} \mathrm{C},(\mathbf{b}) 800{ }^{\circ} \mathrm{C}$, (c) $850{ }^{\circ} \mathrm{C}$, (d) $900{ }^{\circ} \mathrm{C}$, and (e) $950{ }^{\circ} \mathrm{C}$.

Table 3. Lattice parameters, reliability $\mathrm{R}$ factors, crystallite size, and phase content in the Rietveld refinement of XRD patters for $\beta-\mathrm{Ga}_{2} \mathrm{O}_{3}-\alpha-\mathrm{Fe}_{2} \mathrm{O}_{3}$ (HEBM@0-12 h) system, followed by calcination between $600-1000{ }^{\circ} \mathrm{C}$.

\begin{tabular}{|c|c|c|c|c|c|c|c|c|}
\hline \multirow{2}{*}{$\begin{array}{c}\text { Temperature } \\
\left({ }^{\circ} \mathrm{C}\right)\end{array}$} & \multicolumn{3}{|c|}{ Lattice Parameters (£) } & \multicolumn{3}{|c|}{ Reliability R Factors (\%) } & \multirow{2}{*}{$\begin{array}{l}\text { Crystallite Size } \\
\text { (nm) }\end{array}$} & \multirow{2}{*}{$\begin{array}{l}\text { Phase Content } \\
\text { (wt. \%) }\end{array}$} \\
\hline & $a$ & $b$ & $c$ & $\mathbf{R}_{\mathbf{p}}$ & $\mathbf{R}_{\mathrm{wp}}$ & $\mathbf{R}_{\exp }$ & & \\
\hline 600 & 5.0223 & - & 13.6720 & 1.38 & 1.85 & 7.62 & 20.9 & $\mathrm{Ga}: \alpha-\mathrm{Fe}_{2} \mathrm{O}_{3}(100)$ \\
\hline 800 & 5.0261 & - & 13.6720 & 2.15 & 3.75 & 12.75 & 62.2 & $\mathrm{Ga}: \alpha-\mathrm{Fe}_{2} \mathrm{O}_{3}(100)$ \\
\hline 850 & $\begin{array}{c}5.0249 \\
12.3140 \\
5.0932\end{array}$ & $\begin{array}{c}- \\
3.0382 \\
8.7406\end{array}$ & $\begin{array}{c}13.6720 \\
5.8413 \\
9.3867\end{array}$ & 2.37 & 3.89 & 16.90 & $\begin{array}{l}65.1 \\
13.9 \\
40.7\end{array}$ & $\begin{array}{c}\mathrm{Ga}: \alpha-\mathrm{Fe}_{2} \mathrm{O}_{3}(74.52) \\
\beta-\mathrm{Ga}_{2} \mathrm{O}_{3}(12.46) \\
\mathrm{GaFeO}_{3}(13.02)\end{array}$ \\
\hline 900 & $\begin{array}{c}5.0312 \\
12.3140 \\
5.0856\end{array}$ & $\begin{array}{c}- \\
3.0234 \\
8.7527\end{array}$ & $\begin{array}{c}13.6720 \\
5.8553 \\
9.4123\end{array}$ & 1.70 & 2.74 & 18.56 & $\begin{array}{c}54.6 \\
- \\
68.4\end{array}$ & $\begin{array}{c}\mathrm{Ga}: \alpha-\mathrm{Fe}_{2} \mathrm{O}_{3}(27.79) \\
\beta-\mathrm{Ga}_{2} \mathrm{O}_{3}(3.52) \\
\mathrm{GaFeO}_{3}(68.69)\end{array}$ \\
\hline 950 & 5.0839 & 8.7498 & 9.3973 & 2.03 & 3.25 & 22.46 & $>>100$ & $\mathrm{GaFeO}_{3}(100)$ \\
\hline 1000 & 5.0829 & 8.7476 & 9.3963 & 1.99 & 3.22 & 24.71 & $>>100$ & $\mathrm{GaFeO}_{3}(100)$ \\
\hline Errors & \pm 0.0005 & \pm 0.0005 & \pm 0.0005 & & & & \pm 1.5 & \pm 1.2 \\
\hline
\end{tabular}

The above XRD results show that, by first performing an energetic mechanical milling of the oxide mixture $\beta-\mathrm{Ga}_{2} \mathrm{O}_{3}-\alpha-\mathrm{Fe}_{2} \mathrm{O}_{3}$ used to prepare the gallium ortho-ferrite, the calcination temperature drops by $\sim 450{ }^{\circ} \mathrm{C}$, in comparison with the solid-state reaction route [1]. 


\subsection{2. ${ }^{57} \mathrm{Fe}$ Mössbauer Spectroscopy}

The Mössbauer spectra of the samples calcined in the range of $600-1000{ }^{\circ} \mathrm{C}$ (Figure 8a-e) evolve from a magnetic pattern suggesting a distribution of hyperfine magnetic fields (Figure 8a) to a central quadrupole pattern characteristic to the gallium orthoferrite (Figure 8e). Table 4 presents the hyperfine parameters, site assignment, and phase abundance (as given by the computer fit with specialized programs). In Figure 8a, the spectrum of the sample at $600{ }^{\circ} \mathrm{C}$ was fitted best (continuous line) with a distribution of hyperfine magnetic fields reflecting the disorder made by the presence of gallium ions in the hematite lattice and probably by a large particle size distribution in the sample as well. At $800^{\circ} \mathrm{C}$, the Mössbauer pattern (Figure 8b) consists in a prevailing component of hyperfine magnetic field distribution accompanied by a small sextet typical for standard hematite. Figure $8 \mathrm{c}$ exhibits the spectrum at $850{ }^{\circ} \mathrm{C}$ indicating the presence of pure and gallium-doped hematite and the appearance of $\mathrm{GaFeO}_{3}$ phase $(\sim 15 \%)$, represented by the characteristic three quadrupole doublets (denoted S1, S2, and S3 in Table 4). If the spectrum at $900{ }^{\circ} \mathrm{C}$ (Figure $8 \mathrm{~d}$ ) is still revealing the presence of doped hematite $(\sim 30 \%)$, the spectrum at $950{ }^{\circ} \mathrm{C}$ (Figure 8e) indicates only the presence of pure $\mathrm{GaFeO}_{3}$. The three quadrupole doublets $\mathrm{S} 1, \mathrm{~S} 2$, and $\mathrm{S} 3$ are ascribed to the nonequivalent Fe position in gallium orthoferrite structure [27]. One can claim that the formation of the $\mathrm{GaFeO}_{3}$ structure initiates in the temp range of $\sim 800-850{ }^{\circ} \mathrm{C}$, with previous ball milling of the samples.

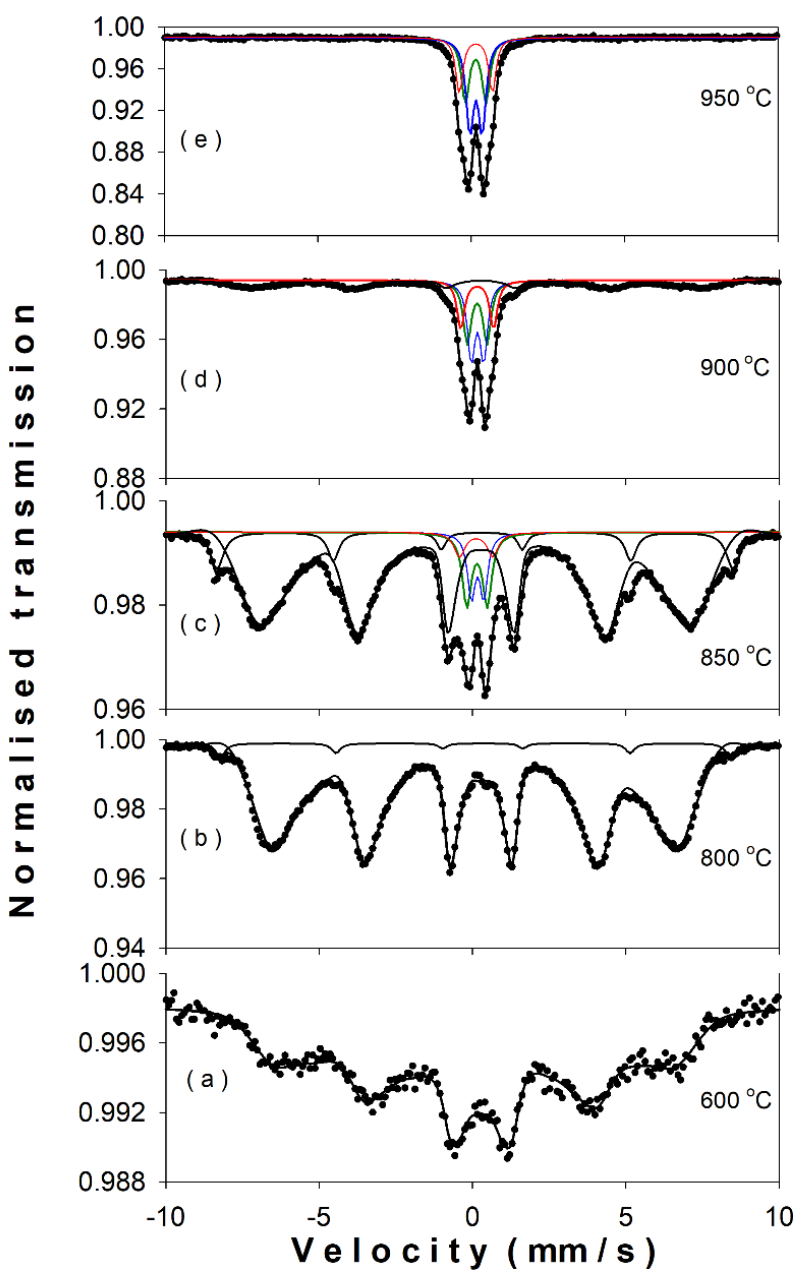

Figure 8. The Mössbauer spectra of the samples calcined at (a) $600{ }^{\circ} \mathrm{C}$, (b) $800{ }^{\circ} \mathrm{C},(\mathbf{c}) 850{ }^{\circ} \mathrm{C}$, (d) $900{ }^{\circ} \mathrm{C}$, and (e) $950{ }^{\circ} \mathrm{C}$. 
Table 4. Mössbauer hyperfine parameters for the system $\beta-\mathrm{Ga}_{2} \mathrm{O}_{3}-\alpha-\mathrm{Fe}_{2} \mathrm{O}_{3}$ after $12 \mathrm{~h}$ of milling and calcination at different temperatures.

\begin{tabular}{|c|c|c|c|c|c|}
\hline $\begin{array}{c}\text { Temperature } \\
\left({ }^{\circ} \mathrm{C}\right)\end{array}$ & $\delta *(\mathrm{~mm} / \mathrm{s})$ & $\Delta(\mathrm{mm} / \mathrm{s})$ & B (T) & $\begin{array}{c}\text { Phase Areas } \\
(\%)\end{array}$ & $\begin{array}{c}\text { Phase } \\
\text { Assignment }\end{array}$ \\
\hline 600 & 0.280 & -0.23 & $6.9-49.2$ & 100 & $\mathrm{Ga}: \alpha-\mathrm{Fe}_{2} \mathrm{O}_{3}$ \\
\hline \multirow{2}{*}{800} & 0.277 & -0.232 & $5.2-49.8$ & 97.0 & $\mathrm{Ga}: \alpha-\mathrm{Fe}_{2} \mathrm{O}_{3}$ \\
\hline & 0.310 & -0.268 & 51.5 & 3.0 & $\alpha-\mathrm{Fe}_{2} \mathrm{O}_{3}$ \\
\hline \multirow{5}{*}{850} & 0.284 & -0.216 & $7.4-52.6$ & 75.5 & $\mathrm{Ga}: \alpha-\mathrm{Fe}_{2} \mathrm{O}_{3}$ \\
\hline & 0.175 & -0.247 & 52.1 & 10 & $\alpha-\mathrm{Fe}_{2} \mathrm{O}_{3}$ \\
\hline & 0.259 & 0.671 & - & 6.7 & $\mathrm{~S} 1-\mathrm{GaFeO}_{3}$ \\
\hline & 0.277 & 0.410 & - & 5.0 & $\mathrm{~S} 2-\mathrm{GaFeO}_{3}$ \\
\hline & 0.229 & 1.091 & - & 2.8 & $\mathrm{~S} 3-\mathrm{GaFeO}_{3}$ \\
\hline \multirow{4}{*}{900} & 0.295 & -0.169 & $16.4-46.3$ & 30 & $\mathrm{Ga}: \alpha-\mathrm{Fe}_{2} \mathrm{O}_{3}$ \\
\hline & 0.262 & 0.648 & - & 24 & $\mathrm{~S} 1-\mathrm{GaFeO}_{3}$ \\
\hline & 0.272 & 0.409 & - & 28 & $\mathrm{~S} 2-\mathrm{GaFeO}_{3}$ \\
\hline & 0.263 & 1.075 & - & 18 & $\mathrm{~S} 3-\mathrm{GaFeO}_{3}$ \\
\hline \multirow{3}{*}{950} & 0.260 & 0.677 & - & 32 & $\mathrm{~S} 1-\mathrm{GaFeO}_{3}$ \\
\hline & 0.269 & 0.406 & - & 43 & $\mathrm{~S} 2-\mathrm{GaFeO}_{3}$ \\
\hline & 0.263 & 1.086 & - & 25 & $\mathrm{~S} 3-\mathrm{GaFeO}_{3}$ \\
\hline \multirow{3}{*}{1000} & 0.260 & 0.681 & - & 32 & $\mathrm{~S} 1-\mathrm{GaFeO}_{3}$ \\
\hline & 0.269 & 0.405 & - & 43 & $\mathrm{~S} 2-\mathrm{GaFeO}_{3}$ \\
\hline & 0.266 & 1.086 & - & 25 & $\mathrm{~S} 3-\mathrm{GaFeO}_{3}$ \\
\hline Errors & \pm 0.005 & \pm 0.010 & \pm 0.5 & \pm 0.06 & \\
\hline
\end{tabular}

* The isomer shift $\delta$ is given relative to $\alpha$-iron.

The phase evolution in the system versus treatment temperature (up to $1000{ }^{\circ} \mathrm{C}$ ) is shown in Figure 9. Figure 10a,b emphasizes the key role of the energetic mechanical activation in significantly reducing the temperature required to obtain the gallium orthoferrite, compared with the common solid phase synthesis procedure.

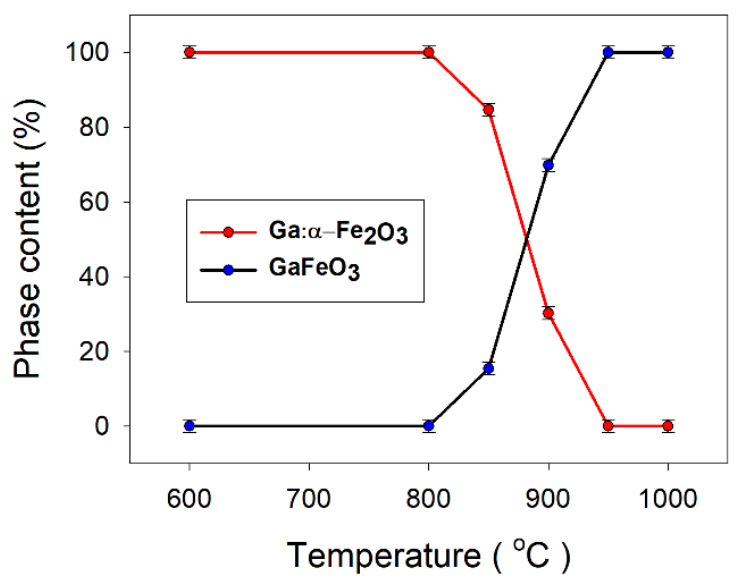

Figure 9. The phase evolution in the system versus treatment temperature, up to $1000{ }^{\circ} \mathrm{C}$.

One notices in Figure $10 \mathrm{a}, \mathrm{b}$ that the calcination at $1000{ }^{\circ} \mathrm{C}$ of the equimolar mixture $\beta-\mathrm{Ga}_{2} \mathrm{O}_{3}-\alpha-\mathrm{Fe}_{2} \mathrm{O}_{3}$ was not enough to generate the crystallization of the desired gallium ortho-ferrite, while the same temperature (even $950^{\circ} \mathrm{C}$ ) was sufficient to obtain the pure phase GFO—starting with the same oxide mixture- that was first energetically milled for several hours. 


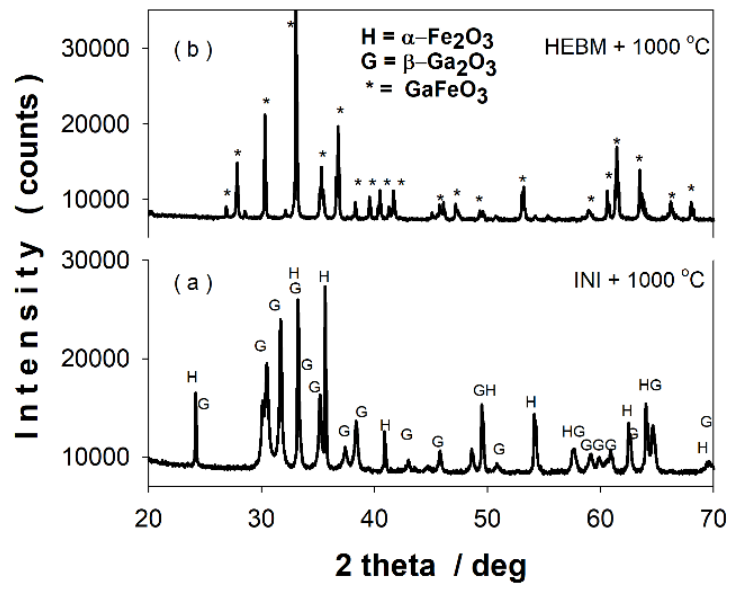

Figure 10. X-ray diffractograms of the initial mixture (a) and after milling (b), calcined at $1000{ }^{\circ} \mathrm{C}$.

\subsubsection{TEM Images}

Figure 11a,b displays the morphology and the selected area electron diffraction (SAED) pattern for the sample after $12 \mathrm{~h}$ of energetic milling followed by calcination for $4 \mathrm{~h}$ at $950{ }^{\circ} \mathrm{C}$, proving the formation of the unique phase $\mathrm{GaFeO}_{3}$. The selected area electron diffraction (SAED) pattern shows a uniform distribution of diffraction spots in circles indicating the random crystallographic orientation of the GFO particles, further suggesting the polycrystalline nature of the material. The calcination process increased the particle size from $\sim 20 \mathrm{~nm}$ to $\sim 150 \mathrm{~nm}$.

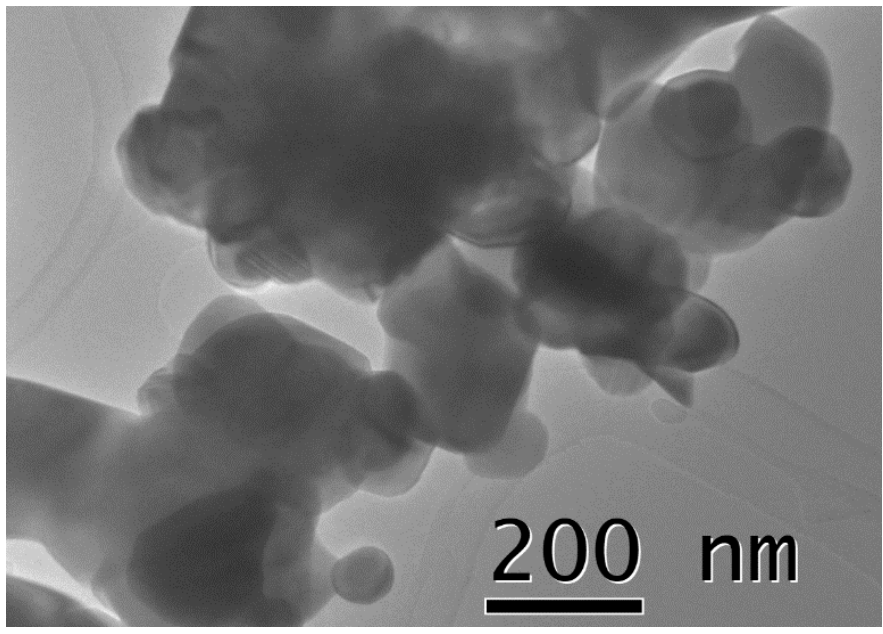

(a)

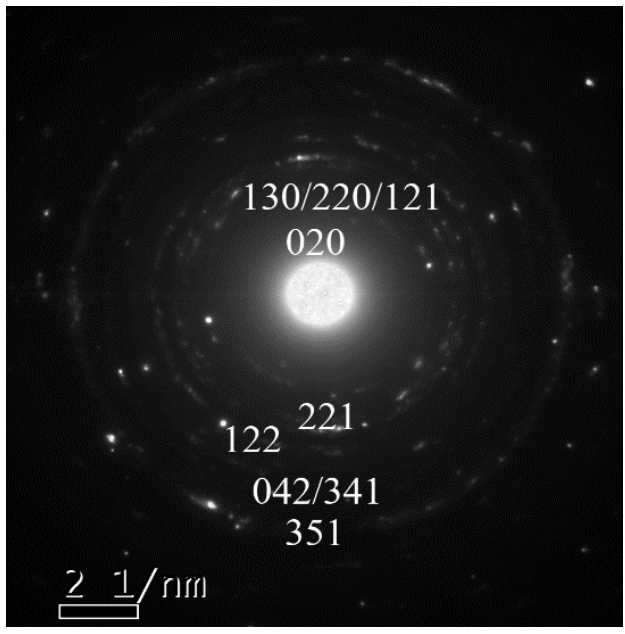

(b)

Figure 11. (a) The morphology of the $\mathrm{GaFeO}_{3}$ powder, obtained after $12 \mathrm{~h}$ of milling and $4 \mathrm{~h}$ of calcination at $950{ }^{\circ} \mathrm{C}$ of the equimolar mixture $\beta-\mathrm{Ga}_{2} \mathrm{O}_{3}-\alpha-\mathrm{Fe}_{2} \mathrm{O}_{3}$; (b) selected area electron diffraction (SAED) pattern for the same sample.

High resolution transmission electron microscopy (HRTEM) image of the GFO sample is presented in Figure 12. The lattice fringes can be distinctly observed in Figure 12, showing the interplanar spacing corresponding to the $\left(\begin{array}{l}2-2 \\ -2\end{array}\right)$ and $\left(\begin{array}{lll}1 & 3 & 1\end{array}\right)$ planes of the $\mathrm{GaFeO}_{3}$ compound, spaced at $2.74 \AA$ and $2.52 \AA$, respectively. The angle of 88 degrees between the two mentioned planes is close to the calculated theoretical value of 88.80 degrees. 


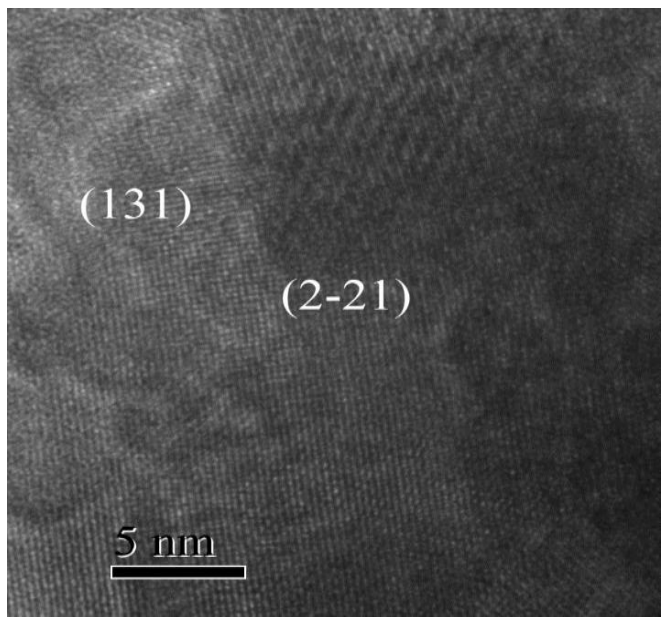

Figure 12. (HRTEM) image of $\mathrm{GaFeO}_{3}$ obtained at $950{ }^{\circ} \mathrm{C}$.

\subsection{Optical Properties of the $\mathrm{Ga}: \alpha-\mathrm{Fe}_{2} \mathrm{O}_{3}$ and $\mathrm{GaFeO} \mathrm{O}_{3}$ Systems}

UV-vis measurements allowed us to obtain data on some optical properties of the investigated samples. The UV-vis absorption edge and band gap energy for all the samples were determined from the room temperature reflectance $(\mathrm{R})$ spectra. The reflectance spectra of $\mathrm{Ga}: \mathrm{Fe}_{2} \mathrm{O}_{3}$ and $\mathrm{GaFeO}_{3}$ are presented in Figure 13a,b. It can be observed that, for all the samples, the reflectance values present slopes with different angles at wavelengths between $500 \mathrm{~nm}$ and $600 \mathrm{~nm}$.

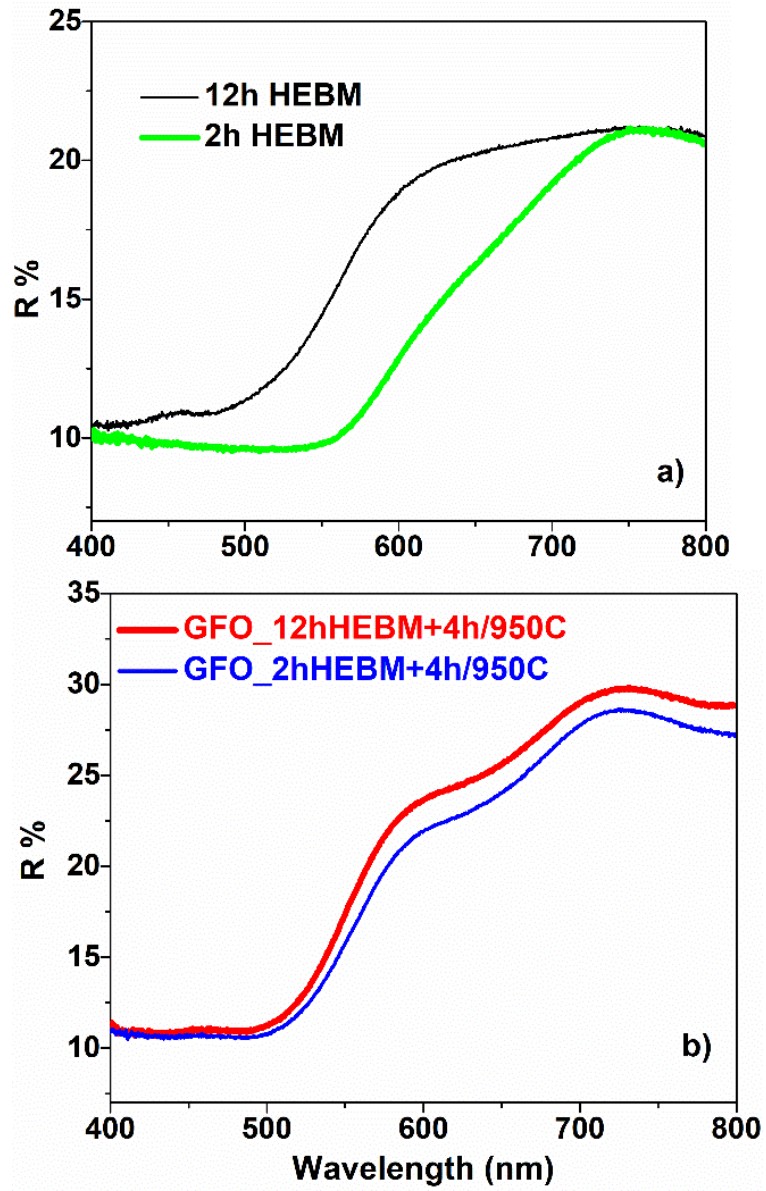

Figure 13. Reflection spectra of (a) $\mathrm{Ga}: \alpha-\mathrm{Fe}_{2} \mathrm{O}_{3}$ and (b) $\mathrm{GaFeO}_{3}$. 
In the case of $\mathrm{Ga}: \alpha-\mathrm{Fe}_{2} \mathrm{O}_{3}$, one can observe an increase of the reflectance (R) with milling time, for wavelengths higher than $500 \mathrm{~nm}$, so the absorbance decreases in this range. A higher value of $\mathrm{R}$ was obtained for the sample subjected to HEBM for $12 \mathrm{~h}$. The same behavior was evidenced in the case of $\mathrm{GaFeO}_{3}$; the lines in Figure $13 \mathrm{~b}$ refer to the samples milled for $2 \mathrm{~h}$ and $12 \mathrm{~h}$, respectively.

The band gap values of the samples were calculated using the representation of Tauc plot $[28,29]$ as presented in Figure 14. Thus, using the Kubelka-Munk function $\mathrm{F}(\mathrm{R})=(1-\mathrm{R})^{1 / 2} / 2 \mathrm{R}$, where $\mathrm{R}$ is the diffuse reflectance, the Tauc's plots $\left.(F(R) h v)^{n} \mathrm{vs} h v\right)$, where $h v$ is the photon energy and $n=\frac{1}{2}$ for direct band gap semiconductors, were represented for all samples. The band gap energies were estimated from the intersections of the tangents to the slopes in the Tauc's plots with the photon energy axis. One notices that the higher the ball milling time, the bigger the band gap energy for both $\mathrm{Ga}: \alpha-\mathrm{Fe}_{2} \mathrm{O}_{3}$ and $\mathrm{GaFeO}_{3}$, expecting better properties toward visible spectrum region. The GFO shows values of Eg of about $2.2 \mathrm{eV}$, indicating possible photocatalytic properties at wavelengths higher than those corresponding to UV range.

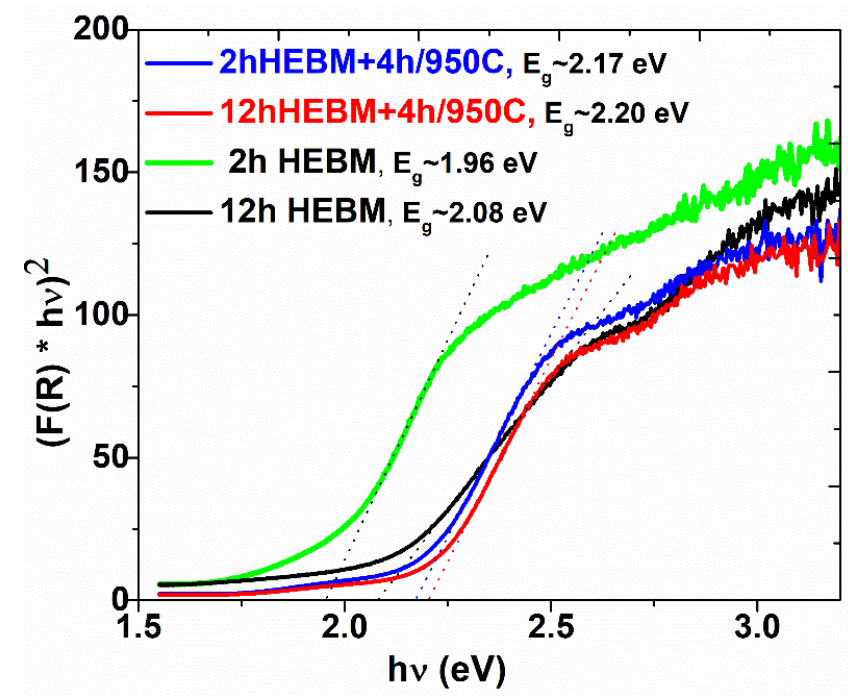

Figure 14. The Tauc graph from which the values of the band gap were extrapolated.

\subsection{Magnetic Properties of the $\mathrm{Ga}: \alpha-\mathrm{Fe}_{2} \mathrm{O}_{3}$ and $\mathrm{GaFeO}_{3}$ Systems}

Figure 15a shows the temperature dependence of the magnetization, measured according to the zero field cooled - field cooled (ZFC-FC) protocol, in a 500 Oe field, for the sample milled for $12 \mathrm{~h}$ and subsequently calcined $4 \mathrm{~h}$ at $600{ }^{\circ} \mathrm{C}\left(\mathrm{Ga}: \mathrm{Fe}_{2} \mathrm{O}_{3}\right)$. One notices a superparamagnetic behavior of the Ga-doped hematite resulting from the divergence of the ZFC and FC curves below $300 \mathrm{~K}$ and the blocking temperature of $203 \mathrm{~K}$. This behavior is consistent with the average of $\sim 15 \mathrm{~nm}$ size of the crystallites, as resulted from XRD data analysis.

The samples calcinated at higher temperatures, in which the gallium orthoferrite (GFO) was formed, showed a totally different behavior of the magnetization as function of temperature. The calcined samples (for $4 \mathrm{~h}$ at $950^{\circ} \mathrm{C}$ ), in which GFO was obtained, showed a similar temperature dependence of magnetization, regardless of the initial milling time (e.g., the samples milled for $2 \mathrm{~h}$ and $12 \mathrm{~h}$, respectively) — see Figure 15b,c. Similar behavior was also found in the magnetization isotherms, measured at $5 \mathrm{~K}$, none of the measured samples reaching saturation, even for an applied field of 6T (see Figure 16a), which suggests a high anisotropy of the compound [30]. The GFO sample obtained after $2 \mathrm{~h}$ of milling time, followed by a calcination of $4 \mathrm{~h} / 950^{\circ} \mathrm{C}$, had a slightly higher coercitive field, Hc $=2690$ Oe, compared to the one obtained after milling for $12 \mathrm{~h}$, which had Hc $=2533$ Oe. For the $\mathrm{Ga}: \mathrm{Fe}_{2} \mathrm{O}_{3}$ compound, we obtained $\mathrm{Hc}=670$ Oe. 

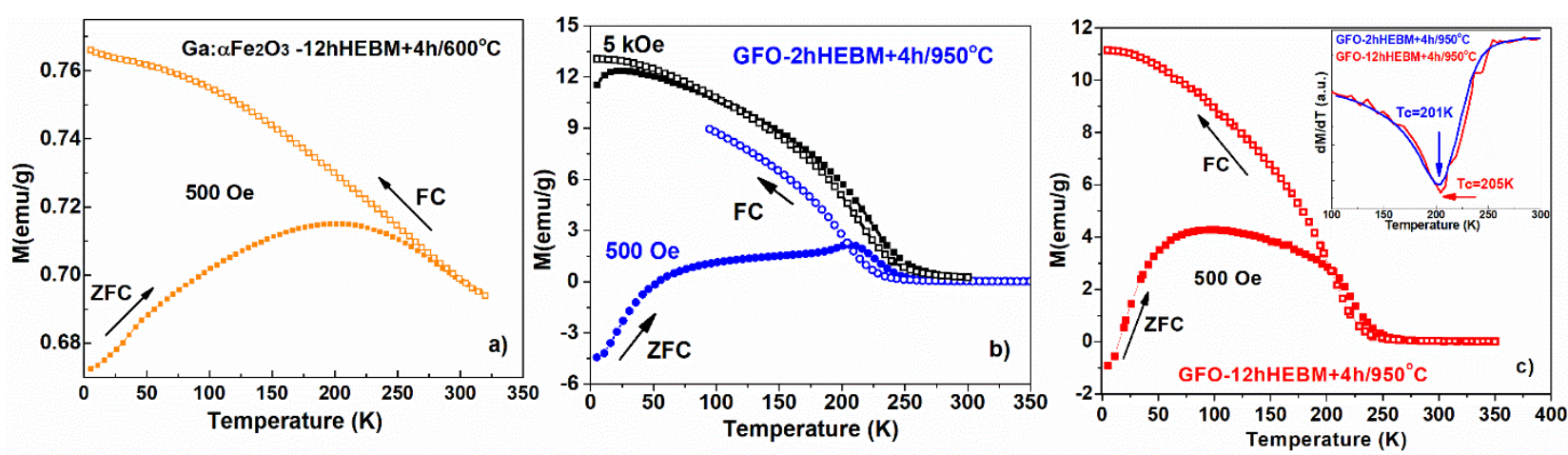

Figure 15. ZFC-FC termomagnetic measurements, recorded in 500 Oe applied magnetic field, for (a) $\mathrm{Ga}_{2} \mathrm{Fe}_{2} \mathrm{O}_{3}$; (b) gallium iron oxide (GFO) obtained after $2 \mathrm{~h}$ of milling and $4 \mathrm{~h}$ of calcination at $950{ }^{\circ} \mathrm{C}$, with black squares representing ZFC-FC measured in $5 \mathrm{kOe}$; (c) GFO obtained after $12 \mathrm{~h}$ of milling and $4 \mathrm{~h}$ of calcination at $950{ }^{\circ} \mathrm{C}$; inset: evaluation of the Curie temperature, from the $\mathrm{dM} / \mathrm{dT}$ derivative.
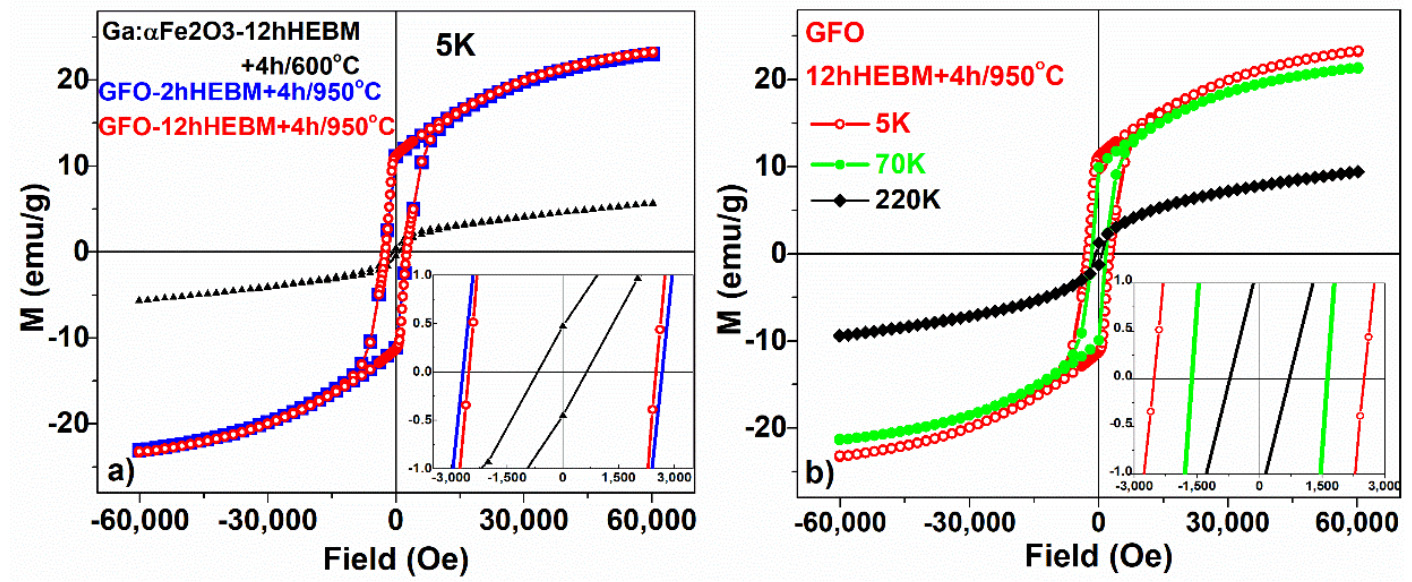

Figure 16. Hysteresis curves measured (a) at $5 \mathrm{~K}$ for $\mathrm{Ga}_{\mathrm{Fe}} \mathrm{O}_{3}$ and for $\mathrm{GaFeO}_{3}$ obtained after previous milling for $2 \mathrm{~h}$ and $4 \mathrm{~h}$ of calcination at $950{ }^{\circ} \mathrm{C}$ (full blue symbols) and $12 \mathrm{~h}$ of milling and calcination (open symbols), respectively; inset: zoomed view to determine coercitivity; (b) for $\mathrm{GaFeO}_{3}$ obtained after $12 \mathrm{~h}$ of milling and calcination $4 \mathrm{~h} / 950{ }^{\circ} \mathrm{C}$ at $5 \mathrm{~K}, 70 \mathrm{~K}$, and $220 \mathrm{~K}$; inset: zoomed view to determine coercitivity.

To have an insight into the temperature dependence of magnetization, the samples were first cooled in zero field (ZFC) and then a 500 Oe was applied on heating. One notices that at low temperatures the magnetization shows negative values for both calcinated samples (Figure 15b,c). First, we must mention that this negative magnetization is not an artifact due to the remnant magnetic field of the SQUID, which was measured to be less than 10 Oe, compared to the applied field of 500 Oe-for measuring the ZFC curves.

The phenomenon of negative magnetization (not due to diamagnetism and accompanied with a magnetization reversal with increasing temperature) is known in literature and has been associated with intrinsic parameters such as: crystal structure, magnetic anisotropy, magnetic exchange interactions, and temperature dependence of sublattice magnetization [31]. The magnetic anisotropy is a key property preventing the rotation of the net magnetic moments in the direction of the applied field, below the compensation temperature.

The study reported by [15] highlights a strong magnetic anisotropy of single crystal GFO. The crystalline structure of GFO, orthorhombic with a space group of Pna21, with four Fe sites, two distorted and one regular octahedral and another one tetrahedral, leads to a complex magnetic behavior of these compounds. In our samples, a strong magnetic anisotropy is suggested by the larger c axis determined from the XRD analysis (around 
$9.3973 \AA$ ), the high coercivity at $5 \mathrm{~K}$, and the fact that even for an applied field of $6 \mathrm{~T}$ none of the measured samples reach saturation (see Figure 16a) [30]. The strong anisotropy of our samples is a prerequisite for the occurrence of negative magnetization.

Another essential condition for the appearance of the negative magnetization phenomenon is the antiparallel ordering between two or more magnetic components showing different temperature dependences of their magnetizations below their magnetic ordering temperatures under the influence of strong magnetic anisotropies [31]. In this context, we have seen studies showing that, in the GFO, the Ga atoms can occupy Fe sites resulting in the formation of "two sublattices constituted by the Ga and Fe sites" [16] with different values of the magnetic moments and probably different temperature dependences, leading to ferrimagnetism. It was shown both theoretically and experimentally that structural disorder may induce changes in magnetic behaviour [30,32,33], for example the strength of the exchange interaction between $\mathrm{Fe}^{3+}$ ions can be modified by the $\mathrm{Ga}$ atoms occupying Fe sites [30]. Moreover, a net magnetization of the GFO can arise from uncompensated ordering of neighbouring sub-lattices [12].

The GFO obtained after $2 \mathrm{~h}$ of milling and $4 \mathrm{~h}$ of calcination at $950{ }^{\circ} \mathrm{C}$ shows a maximum (i.e., a cusp in the temperature dependence of magnetization) before reaching the magnetic order transition. The magnetic order-disorder transition temperatures were determined as the differential minimum from the first derivative of the temperature dependent magnetization on the field cooling (FC) (see inset of Figure 15c). For the GFO sample obtained after $2 \mathrm{~h}$ of milling and $4 \mathrm{~h}$ of calcination at $950{ }^{\circ} \mathrm{C}$ the Curie ferromagneticparamagnetic transition (Tc) takes place at $201 \mathrm{~K}$, while for the GFO obtained after $12 \mathrm{~h}$ of milling and $4 \mathrm{~h}$ of calcination at $950{ }^{\circ} \mathrm{C}$, we obtained $205 \mathrm{~K}$ as transition temperature. The obtained values for the magnetic order-disorder transitions are comparable with the values obtained on GFO prepared by solid state reaction in $[1,12]$.

On cooling the samples in 500 Oe, i.e., the FC curves in Figure 15, a divergence was noticed compared to the ZFC curve. The difference between FC and ZFC magnetizations is known to be related to the magnitude and the temperature variation of coercivity, which is a measure of the magnetic anisotropy [34]. A large coercitivity at low temperatures leads to the increase of the FC magnetization.

The hysteresis curves measured for $\mathrm{GaFeO}_{3}$ obtained after $12 \mathrm{~h}$ of HEBM and calcination for $4 \mathrm{~h} / 950{ }^{\circ} \mathrm{C}$ at $5 \mathrm{~K}, 70 \mathrm{~K}$, and $220 \mathrm{~K}$ are shown in Figure $16 \mathrm{~b}$. The coercitive field is much higher at $5 \mathrm{~K}$ (2533 Oe), compared to $70 \mathrm{~K}$ (1618 Oe) and $220 \mathrm{~K}(719 \mathrm{Oe})$. As mentioned in [12], since coercivity is related to magnetic anisotropy, the irreversible magnetic behavior reflects the role of anisotropy in determining the shapes of FC and ZFC curves below the ordering temperature.

The cusp noticed for the $\mathrm{GaFeO}_{3}$ sample obtained after $2 \mathrm{~h}$ milling and calcinated $4 \mathrm{~h}$ at $950{ }^{\circ} \mathrm{C}$ moves to much lower temperatures if the applied field increases from 500 Oe to 5000 Oe (see Figure 15b, black curve, the cusp moving at approx. $25 \mathrm{~K}$ ). The bifurcation between the ZFC and FC samples and the presence as well as the temperature behavior of the mentioned cusp, originate in the anisotropy field of the GFO [12,30,32]. The origin of magneto-crystalline anisotropy in GFO received a possible explanation in terms of the large orbital angular momentum due to the off-center displacement of $\mathrm{Fe}^{3+}$ ions [30].

\section{Conclusions}

$\mathrm{GaFeO}_{3}(\mathrm{GFO})$ ortho-ferrite was synthesized by high-energy ball milling (HEBM) and post-annealing pathway starting with an equimolar mixture of $\beta-\mathrm{Ga}_{2} \mathrm{O}_{3}$ and $\alpha-\mathrm{Fe}_{2} \mathrm{O}_{3}$. X-ray powder diffraction, ${ }^{57} \mathrm{Fe}$ Mössbauer spectroscopy, and transmission electron microscopy were used to study the phase evolution in $\beta-\mathrm{Ga}_{2} \mathrm{O}_{3}-\alpha-\mathrm{Fe}_{2} \mathrm{O}_{3}$ system under HEBM conditions, as well as after calcination. Energetic mechanical milling for $2-12 \mathrm{~h}$ and subsequent annealing up to $1000{ }^{\circ} \mathrm{C}$ were performed. Pure, well-crystallized GFO phase was obtained after $12 \mathrm{~h}$ of milling and post-annealing pathway at $950{ }^{\circ} \mathrm{C}(4 \mathrm{~h})$. This reduced annealing temperatures and times are the main advantages of our preparation route. Commonly the GFO is prepared by solid phase reaction between $\beta-\mathrm{Ga}_{2} \mathrm{O}_{3}$ and $\alpha-\mathrm{Fe}_{2} \mathrm{O}_{3}$ at relative high 
temperature $\left(\sim 1400{ }^{\circ} \mathrm{C}\right)$ and long reaction time $(5-20 \mathrm{~h})$. Our results evidence that both mechanical milling and calcination are important; it was shown that the calcination of the initial $\beta-\mathrm{Ga}_{2} \mathrm{O}_{3}-\alpha-\mathrm{Fe}_{2} \mathrm{O}_{3}$ mixture up to $1000{ }^{\circ} \mathrm{C}$ results in a gallium-doped hematitelike phase. The GFO structure was obtained only after calcination at $950{ }^{\circ} \mathrm{C}$ of the oxide mixture $\beta-\mathrm{Ga}_{2} \mathrm{O}_{3}-\alpha-\mathrm{Fe}_{2} \mathrm{O}_{3}$, previously subjected to HEBM for 12 hours. The magnetic and optic properties of the investigated samples were revealed by magnetic and UV-vis measurements respectively. The Ga-doped hematite exhibits superparamagnetic behavior with a blocking temperature of $203 \mathrm{~K}$. It was found that the magnetic properties of the final product $\mathrm{GaFeO}_{3}$ were independent of the milling time of the initial oxide mixture $\beta-\mathrm{Ga}_{2} \mathrm{O}_{3}-\alpha-\mathrm{Fe}_{2} \mathrm{O}_{3}$, in the range of 2-12 h. The band gap energy $\left(\mathrm{E}_{\mathrm{g}}\right)$ determined from Tauc's plots was close to $2.2 \mathrm{eV}$, suggesting possible applications as photocatalytic material. This work also evidences the crucial role of energetic mechanical activation in the synthesis of $\mathrm{GaFeO}_{3}$ ortho-ferrite via mechanochemistry.

Author Contributions: Conceptualization, L.D., M.F. and F.T.; methodology, L.D.; software, L.D. and M.E.; validation, L.D., F.T., M.E., F.V. and I.M.; investigation, L.D., F.T., M.E., F.V., I.M., T.P. and B.P.; resources, L.D.; data curation, L.D. and F.T.; writing-original draft preparation, L.D. and F.T.; writing—review and editing, L.D., F.T., B.P. and I.M.; visualization, L.D., F.T., M.E., F.V., I.M., T.P. and B.P.; supervision, L.D. and F.T.; project administration, L.D.; funding acquisition, L.D. and F.T. All authors have read and agreed to the published version of the manuscript.

Funding: Project PCCDI 47 Contract 597/2018, CPN-III-P2-2.1-PED-2019: Contract 324PED/2020 and Contract 493PED/2020 and Core Program project PN09-450103 funded by the Romanian Ministry of Education and Research.

Institutional Review Board Statement: Not applicable.

Informed Consent Statement: Not applicable.

Data Availability Statement: Data can be provided by the corresponding author upon reasonable request.

Conflicts of Interest: The authors declare no conflict of interest.

\section{References}

1. Bakr Mohamed, M.; Senyshyn, A.; Ehrenberg, H.; Fuess, H. Structural, magnetic, dielectric properties of multiferroic GaFeO 3 prepared by solid state reaction and sol-gel methods. J. Alloy Comp. 2010, 492, L20-L27. [CrossRef]

2. Dhanasekaran, P.; Gupta, M.N. Factors affecting the production of $\mathrm{H}_{2}$ by water splitting over a novel visible light-driven photocatalysts $\mathrm{GaFeO}_{3}$. Int. J. Hydrog. Energy 2012, 37, 4897-4907. [CrossRef]

3. Liang, C.H.; Meng, G.W.; Wang, G.Z.; Wang, Y.W.; Zhang, L.D.; Zhang, S.Y. Catalytic synthesis and photoluminescence of beta- $\mathrm{Ga}_{2} \mathrm{O}_{3}$ nanowires. Appl. Phys. Lett. 2001, 78, 3202-3204. [CrossRef]

4. Li, X.Y.; Trinchi, A.; Wlodarski, W.; Galatsis, K.; Kalantar-zadehet, K. Investigation of the oxygen gas sensing performance of $\mathrm{Ga}_{2} \mathrm{O}_{3}$ thin films with different dopants. Sens. Actuators 2003, B93, 431-434. [CrossRef]

5. Hou, Y.D.; Wu, L.; Wang, X.C.; Ding, Z.X.; Li, Z.H.; Fu, X.Z. Photocatalytic performance of alpha-, beta-, and gamma-Ga $2 \mathrm{O}_{3}$ for the destruction of volatile aromatic pollutants in air. J. Catal. 2007, 250, 12-18. [CrossRef]

6. Krishnamoorthy, S.; Rivas, J.A.; Amiridis, M.D. Catalytic oxidation of 1,2-dichlorobenzene over supported transition metal oxides. J. Catal. 2000, 193, 264-272. [CrossRef]

7. Carraro, G.; Barreca, D.; Bekermann, D.; Montini, T.; Gasparotto, A.; Gombac, V.; Maccato, C.; Fornasiero, P. Supported F-Doped alpha- $\mathrm{Fe}_{2} \mathrm{O}_{3}$ Nanomaterials: Synthesis, Characterization and Photo-Assisted H-2 Production. J. Nanosci. Nanotechnol. 2013, 13, 4962-4968. [CrossRef]

8. Rettig, F.; Moos, R. $\alpha$-Iron oxide: An intrinsically semiconducting oxide material for direct thermoelectric oxygen sensors. Sens. Actuators B Chem. 2010, 145, 685-690. [CrossRef]

9. Ohkoshi, S.; Kuroki, S.; Sakurai, S.; Matsumoto, K.; Sato, K.; Sasaki, S. A Millimeter-Wave Absorber Based on Gallium-Substituted $\varepsilon$-Iron Oxide Nanomagnets. Angew. Chem. Int. Ed. 2007, 46, 8392-8395. [CrossRef]

10. Sena, S.; Chakraborty, N.; Rana, P.; Narjinary, M.; Mursalina, S.D.; Tripathyb, S.; Pradhan, D.K.; Sen, A. Nanocrystalline gallium ferrite: A novel material for sensing very low concentration of alcohol vapour. Ceram. Int. 2015, 41, 10110-10115. [CrossRef]

11. Kujur, V.S.; Singh, S. Structural, magnetic, optical and photocatalytic properties of $\mathrm{GaFeO}_{3}$ nanoparticles synthesized via non-aqueous solvent-based sol-gel route. J. Mater. Sci. Mater. Electron. 2020, 31, 17633-17646. [CrossRef]

12. Han, T.C.; Chen, T.Y.; Lee, Y.C. Grain size effect on site-disorder and magnetic properties of multiferroic $\mathrm{GaFeO}_{3}$ nanoparticles. Appl. Phys. Lett. 2013, 103, 232405. [CrossRef] 
13. Zhang, M.H.; Yasui, S.; Katayama, T.; Rao, B.N.; Wen, H.Q.; Pan, X.H.; Tang, M.B.; Ai, F.; Itoh, M. Epitaxial Growth of Orthorhombic $\mathrm{GaFeO}_{3}$ Thin Films on $\mathrm{SrTiO}_{3}$ (111) Substrates by Simple Sol-Gel Method. Materials 2019, 12, 254. [CrossRef] [PubMed]

14. Sun, X.; Tiwari, D.; Fermin, D.J. High Interfacial Hole-Transfer Efficiency at GaFeO3 Thin Film Photoanodes. Adv. Energy Mater. 2020, 2002784. [CrossRef]

15. Tachiyama, K.; Yasui, S.; Aroor Rao, B.; Dazai, T.; Usami, T.; Taniyama, T.; Katayama, T.; Hamasaki, Y.; Yu, J.; He, H.; et al. Magnetic properties of Single Crystal $\mathrm{GaFeO}_{3}$. MRS Adv. 2019, 4, 61-66. [CrossRef]

16. Zhao, Z.M.; An, F.; Tian, F.G.; Zhang, Y.; Zhu, Q.F.; Chen, L.; Zhong, G.K.; Xie, S.H. Room temperature multiferroic properties of electrospun gallium ferrite nanofibers. J. Appl. Phys. 2020, 127, 134101. [CrossRef]

17. Jacobson, C.J.H.; Jiang, J.Z.; Mørup, S.; Clause, B.S.; Topsoe, H. Ammonia synthesis over multi-promoted iron catalysts obtained by high-energy ball-milling. Catal. Lett. 1999, 61, 115-120. [CrossRef]

18. Suryanarayana, C.; Al-Aqeeli, N. Mechanically alloyed nanocomposites. Prog. Mater. Sci. 2013, 58, 383-502. [CrossRef]

19. Delogu, F.; Gorrasi, G.; Sorrentino, A. Fabrication of polymer nanocomposites via ball milling: Present status and future perspectives. Prog. Mater. Sci. 2017, 86, 75-126. [CrossRef]

20. Sorescu, M.; Diamandescu, L. Mechanochemical and magnetomechanical synthesis of hematite nanoparticles. Hyperfine Interact. 2010, 196, 349-358. [CrossRef]

21. Lemine, O.M.; Ghiloufi, I.; Bououdina, M.; Khezami, L.; M’hamed, M.O.; Hassan, A.T. Nanocrystalline Ni doped alpha-Fe ${ }_{2} \mathrm{O}_{3}$ for adsorption of metals from aqueous solution. J. Alloy Comp. 2014, 588, 592-595. [CrossRef]

22. Sorescu, M.; Diamandescu, L.; Wood, J. Synthesis and characterization of the $x \mathrm{ZnO}-(1-x) \alpha-\mathrm{Fe}_{2} \mathrm{O}_{3}$ nanoparticles system. J. Phys. Chem. Solids 2007, 68, 426-430. [CrossRef]

23. Sorescu, M.; Xu, T.; Burnett, J.D.; Aitken, J.A. Investigation of $\mathrm{LaFeO}_{3}$ perovskite growth mechanism through mechanical ball milling of lanthanum and iron oxides. J. Mater. Sci. 2011, 46, 6709-6717. [CrossRef]

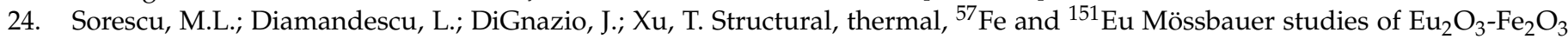
ceramic nanostructures. Ceram. Int. 2015, 41, 1579-1588. [CrossRef]

25. Szafraniak-Wiza, I.; Bednarski, W.; Waplak, S.; Hilczer, B.; Pietraszko, A.; Kępiński, L. Multiferroic BiFeO 3 nanoparticles studied by electron spin resonance, Diffraction and Transmission Electron Microscopy Methods. J. Nanosci. Nanotechnol. 2009, 9, $3246-3251$. [CrossRef] [PubMed]

26. Rietveld, H.M. A profile refinement method for nuclear and magnetic structures. J. Appl. Crystallogr. 1969, 2, 65-71. [CrossRef]

27. Reddy, V.R.; Sharma, K.; Gupta, A.; Banerjee, A. Magnetic anisotropy and sub-lattice magnetization study of polycrystalline magneto-electric $\mathrm{Ga}_{2-\mathrm{x}} \mathrm{Fe}_{\mathrm{x}} \mathrm{O}_{3}$. J. Magn. Magn. Mater. 2014, 362, 97-103. [CrossRef]

28. Tauc, J.; Grigorovici, J.R.; Vancu, A. Optical Properties and Electronic Structure of Amorphous Germanium. Phys. Status Solidi B 1966, 15, 627-637. [CrossRef]

29. Diamandescu, L.; Vasiliu, F.; Tarabasanu-Mihaila, D.; Feder, M.; Vlaicu, A.M.; Teodorescu, C.M.; Macovei, D.; Enculescu, I.; Parvulescu, V.; Vasile, E. Structural and photocatalytic properties of iron- and europium-doped $\mathrm{TiO}_{2}$ nanoparticles obtained under hydrothermal conditions. Mater. Chem. Phys. 2008, 112, 146-153. [CrossRef]

30. Sharma, K.; Reddy, V.R.; Gupta, A.; Banerjee, A.; Awasthi, A.M. Magnetic and ${ }^{57}$ Fe Mössbauer study of magneto-electric GaFeO $3_{3}$ prepared by the sol-gel route. J. Phys. Condens. Matt. 2013, 25, 076002C. [CrossRef]

31. Kumar, A.; Yusuf, S.M. The phenomenon of negative magnetization and its implications. Phys. Rep. 2015, 556, 1-34. [CrossRef]

32. Raies, I.; Aldulmani Sharah, A.A.; Farhat, L.B.; Amami, M. Effect of restricted structural deformation on magnetic and electrical properties in $\mathrm{GaFeO}_{3}$ with $\mathrm{Zn}$, Ti co-doping. J. Mater. Res. Tech. 2020, 9, 1673-1682. [CrossRef]

33. Han, M.J.; Ozaki, T.; Yu, J. Magnetic ordering and exchange interactions in multiferroic GaFeO3. Phys. Rev. B 2007, 75, 060404(R). [CrossRef]

34. Joy, P.A.; Kumar Anil, P.S.; Date, S.K. The relationship between field-cooled and zero-field-cooled susceptibilities of some ordered magnetic systems. J. Phys. Condens. Matter 1998, 10, 11049-11054. [CrossRef] 